\title{
GRATIDÃO A BENFEITORES E REFLEXÕES SOBRE EDUCAÇÃO MORAL
}

\author{
FELIPE QUEIROZ SIQUEIRA \\ Universidade Federal do Rio Grande do Sul (UFRGS) \\ LIA BEATRIZ DE LUCCA FREITAS \\ Universidade Federal do Rio Grande do Sul (UFRGS)
}

\begin{abstract}
RESUMO
Documentos como os Parâmetros Curriculares Nacionais (PCN) enfatizam a relevância da educação moral. Tratar de virtudes em ambiente escolar é importante, uma vez que estimula um convívio mais genuíno entre os indivíduos. A gratidão é fundamental para criar, manter ou fortalecer vínculos, originando um ciclo de ajuda e suporte mútuos, podendo contrabalançar valores típicos da sociedade contemporânea, como o individualismo e o hedonismo. Entretanto, em uma relação de gratidão é necessário investigar não apenas características do beneficiário, mas também do benfeitor. Este estudo, então, teve o objetivo de investigar quem são os benfeitores apontados por crianças e adolescentes, além de verificar relações entre tipos de benfeitor, idade, tipos de desejo e formas de gratidão. Participaram 283 crianças e adolescentes de 7 a 14 anos. Utilizou-se a versão em português do The Wishes and Gratitude Survey (WAGS). Realizou-se uma análise de conteúdo das respostas e rodaram-se análises descritivas e testes qui-quadrado com as variáveis de interesse. A maioria dos jovens mencionou benfeitores próximos. Essa menção foi mais frequente em crianças do que em adolescentes. Tipos de benfeitor relacionaram-se a tipos de desejo, mas não a formas de gratidão. Os resultados contribuem para um melhor entendimento dessa virtude, o que permite a elaboração de estratégias para estimular o desenvolvimento moral dos alunos.
\end{abstract} Palavras-chave: gratidão; benfeitores; educação moral. 


\begin{abstract}
Documents such as the Parâmetros Curriculares Nacionais (PCN) emphasize the relevance of the moral education. Dealing with virtues in the school environment is important, because it stimulates more genuine relationships between individuals. Gratitude is essential to create, maintain, or strengthen the bonds, creating a cycle of mutual help and support, counterbalancing typical values of contemporary society, such as individualism and hedonism. However, in a relationship of gratitude, it is necessary to investigate, not only the beneficiary's features, but also the benefactor's ones. This study aimed to investigate who are the benefactors mentioned by children and adolescents, and to verify associations between types of benefactor, age, types of wishes and forms of gratitude. Two hundred and eighty-three children and adolescents participated in this research. We used a Portuguese version of The Wishes and Gratitude Survey (WAGS). We performed a content analysis of the answers and, then, descriptive analyzes and chi-square tests with the variables of interest. Most of the young people mentioned close benefactors. This kind of mention was more frequent in children than in adolescents. Types of benefactor related to types of wishes, but not to forms of gratitude. The results contribute to a better understanding of this virtue, which make possible the development of strategies to stimulate students' moral development.
\end{abstract}

Keywords: gratitude; benefactors; moral education.

\title{
INTRODUÇÃO
}

Os Parâmetros Curriculares Nacionais (BRASIL, 1998), conhecidos como PCN, contêm sugestões para o ensino do país e, segundo Galian (2014), servem como inspiração para outros documentos, tais como as Diretrizes Curriculares Nacionais (BRASIL, 2015) e a Base Nacional Comum Curricular (BRASIL, 2018). Conforme os PCN, os profissionais da educação precisam incentivar a construção da moralidade em seus alunos. O desen- 
volvimento adequado de crianças e adolescentes não se resume à aquisição de conhecimentos teóricos, mas passa também pela constituição da moral (ARAGÃO et al., 2018; PIAGET, 1998).

Assim sendo, é importante que se trabalhem as virtudes em ambiente escolar, uma vez que, segundo La Taille (2018), elas permitem um convívio mais genuíno entre os indivíduos. A justiça, por exemplo, remete à consideração e preocupação com o outro, apontando para uma questão de direitos e deveres (COUTO; ALENCAR, 2017). Já a generosidade remete ao cuidado, à conexão com os outros (VALE; ALENCAR, 2009). Embora a justiça e a generosidade sejam bastante investigadas na área da psicologia moral (DELLAZZANA-ZANON et al., 2013), existem outras virtudes importantes. A gratidão é fundamental para criar, manter ou fortalecer vínculos, originando um ciclo de ajuda e suporte mútuos (RAVA; FREITAS, 2013). Além disso, pode contrabalançar valores como o individualismo e o hedonismo, típicos da sociedade contemporânea (FREITAS et al., 2016). A seguir, apresentam-se a definição de gratidão e evidências de que ela se desenvolve desde a infância.

\section{GRATIDÃO E SEU DESENVOLVIMENTO EM CRIANÇAS E ADOLESCENTES}

A gratidão ocorre quando: uma pessoa - o benfeitor proporciona um benefício intencional, livre e gratuitamente para outra - o beneficiário; o beneficiário entende a intencionalidade do benfeitor e valoriza positivamente não apenas o benefício recebido, mas também o próprio benfeitor; e o beneficiário, se houver oportunidade, retribui com algo que agrade ou beneficie seu benfeitor (MCCONNELL, 2017; TUDGE et al., 2018). Há evidências de que essa virtude se desenvolve desde a infância. O primeiro estudo que se tem conhecimento sobre a evolução da gratidão é o de Baumgarten-Tramer (1938), realizado com 1.059 jovens de 7 a 15 anos de idade, na Suíça. Os participantes responderam a duas perguntas: "O que tu mais queres?"; e "O 
que tu farias para a pessoa que te desse o que tu mais queres?”. Ao analisarem-se as respostas da segunda questão, verificaram-se diferenças na maneira como os jovens expressam a gratidão. A gratidão verbal se refere a dizer obrigado. Essa forma mostrou-se frequente em todas as faixas etárias.

A gratidão concreta é caracterizada por retribuir com algo representativo do seu ponto de vista e não necessariamente do benfeitor. Esse tipo foi mais frequente em crianças menores e mais raro entre os adolescentes. A gratidão conectiva se refere à tendência de retribuir com algo que o benfeitor precise ou aprecie, tendo sido mais frequente em participantes com $11 \mathrm{e}$ 12 anos. A gratidão finalística remete à tendência de retribuir a alguém por meio de uma ação que possa ser útil para conquistar o benefício desejado ou que promova seu próprio desenvolvimento. Esse último tipo foi bastante raro, tendo sido mencionado por apenas alguns indivíduos.

Estudos realizados no Brasil (FREITAS et al., 2011; FREITAS et al., 2016), nos Estados Unidos da América (TUDGE et al., 2015) e na China (WANG; WANG; TUDGE, 2015), com jovens de 7 a 14 anos, sobre tipos de desejos, formas de gratidão e suas relações encontraram três tipos de desejos: hedonistas, relativos ao bem-estar próprio no futuro (BEP) e relacionados ao bem-estar de outros (BEO). Verificaram-se as três principais formas de gratidão identificadas por Baumgarten-Tramer (1938): verbal, concreta e conectiva.

De maneira geral, os resultados indicaram que existem mudanças nos tipos de desejos e nas formas de gratidão relacionadas à idade, em todos esses países. As mudanças, porém, não são as mesmas em todas as culturas. Quanto às formas de gratidão, por exemplo, observou-se que, com a idade, a frequência de gratidão concreta diminui no Brasil e nos EUA, mas se manteve relativamente estável na China.

As conclusões de uma investigação transcultural realizada em sete países (Brasil, China, Coréia do Sul, EUA, Guatemala, 
Rússia e Turquia) apontam nessa mesma direção (MENDONÇA et al., 2018). Além disso, encontraram-se diferenças também na frequência com que os tipos de gratidão foram expressos nos diversos países. Nesse sentido, chama atenção o fato de que, quando comparados aos demais, Brasil e EUA foram os dois países em que a gratidão conectiva - a forma que mais se aproxima da virtude gratidão - apareceu com menor frequência, 36\% e 38,6\% respectivamente. Na China $(69,8 \%)$ e na Coréia do Sul $(57,5 \%)$ essa forma de gratidão apresentou as maiores frequências.

Essas pesquisas evidenciam que, em diversas culturas, há desenvolvimento da gratidão no decorrer da infância e da adolescência. Entretanto, examinaram-se apenas aspectos do beneficiário. A gratidão, contudo, emerge em uma relação entre, no mínimo, duas pessoas (RAVA; FREITAS, 2013), sendo importante também examinar o outro polo dessa relação: o benfeitor. A seguir, apresentam-se estudos que enfocam o benfeitor e sugerem que suas características podem influenciar a gratidão.

\section{GRATIDÃO E BENFEITORES}

A literatura que trata do benfeitor não é homogênea: examinaram-se diversas de suas particularidades e empregaram-se diferentes métodos nas pesquisas sobre esse assunto. Uma característica importante é a proximidade que o benfeitor tem com o beneficiário. Becker e Smenner (1986) realizaram um estudo nos Estados Unidos, com 250 crianças de 3 e 4 anos, para verificar essa questão. No experimento, apenas $37 \%$ dos participantes agradeceram verbalmente ao receberem uma recompensa de alguém não familiar - a maioria não disse obrigado ao benfeitor desconhecido, mesmo que o contexto fosse apropriado.

Nessa mesma perspectiva, Gordon et al. (2004) fizeram uma investigação a partir de 358 respostas de participantes norte-americanos de 4 a 12 anos, a qual obteve resultados sobre proximidade na gratidão, embora não tivesse sido delineada com tal objetivo. Os jovens, ao serem questionados sobre essa 
virtude, mencionaram com maior frequência pessoas próximas: membros da família $(67 \%)$ e amigos $(25,6 \%)$. Com menor frequência, citaram indivíduos não familiares, identificados por suas profissões: professores $(23,3 \%)$, policiais, bombeiros e ajudantes $(10,6 \%)$ e presidente da República $(2,6 \%)$.

Vale e Alencar (2009) realizaram um estudo com 30 jovens brasileiros de 7,10 e 13 anos com o intuito de investigar seus juízos em relação a pessoas que beneficiaram indivíduos com distintos níveis de proximidade: amigos, desconhecidos e inimigos. Para a maioria dos entrevistados, os inimigos não são merecedores de ações generosas. A maior parte também julgou que o benfeitor deveria ser generoso com amigos e desconhecidos. Entretanto, no geral, as crianças de 7 e 10 anos afirmaram que a generosidade do benfeitor para com um amigo deve ser mais intensa do que para com um desconhecido.

As crianças mais novas parecem ter preferência por benfeitores próximos, seja para decidir quem deve realizar atos generosos (VALE; ALENCAR, 2009), seja para escolher a quem expressar gratidão (BECKER; SMENNER, 1986; GORDON et al., 2004). Tais considerações encontram respaldo em Piaget (1994, 2014), segundo o qual crianças de até 11 ou 12 anos possuem a moralidade baseada principalmente na afeição para com os pais e outros indivíduos próximos. Apenas a partir da aquisição do pensamento formal e da moral autônoma, elas tornam-se capazes de interagir moralmente com a ideia abstrata de pessoa. A começar dessa fase, então, os adolescentes têm o seu círculo social ampliado e tornam-se capazes de efetuar juízos cada vez mais universalizáveis. Em função disso, as pessoas que os cercam são passíveis de um mesmo tratamento, guiado por princípios e ideais, ainda que não sejam membros da família ou amigos íntimos.

A distância interpessoal não é, todavia, a única característica do benfeitor que parece afetar a gratidão. Morgan e Gulliford (2018) realizaram estudo transcultural para examinar fatores que influenciam a gratidão, da qual participaram crianças, entre 8 e 11 
anos (270 do Reino Unido e 531 da Austrália), adolescentes, entre 11 e 18 anos (271 do Reino Unido e 2.364 da Austrália), e adultos, entre 18 e 85 anos (192 do Reino Unido e 234 da Austrália).

Em ambos os países as crianças julgaram mais apropriado expressar gratidão a benfeitores que se colocam em risco para oferecer ajuda, em comparação aos que não se encontram nessa situação. Elas, contudo, encontraram dificuldades em identificar intenções não benevolentes, ou seja, "segundas intenções" do benfeitor. Os adolescentes tenderam a valorizar mais a intenção do benfeitor, mesmo quando o benefício era indesejado, em comparação com os adultos. Tanto os adolescentes quanto os adultos expressaram altos níveis de gratidão em situações nas quais não era possível identificar as intenções e motivações do benfeitor. Entretanto, os adultos relataram maior nível de gratidão em comparação aos adolescentes quando o benfeitor corria maior risco de vida; além disso, demonstraram maior habilidade em identificar ações não benevolentes do que crianças e adolescentes.

Siqueira e Freitas (2016) também realizaram uma investigação que envolveu a habilidade de identificar ações de benfeitores não propriamente benevolentes. Esse estudo foi realizado com 28 crianças brasileiras de 6, 9 e 12 anos e teve por objetivo investigar se a humildade do benfeitor (ou sua falta) influencia o sentimento de obrigatoriedade de retribuir um favor, e verificar diferenças etárias. Os jovens avaliaram duas histórias: (a) uma em que o benfeitor foi humilde (não se gabou de seu ato generoso) e (b) outra em que ele não o foi.

Participantes de todas as idades entenderam que a falta de humildade do benfeitor seria motivo para que ele não recebesse uma retribuição do beneficiário. No entanto, houve uma tendência de os jovens de 9 e 12 anos levarem em conta a ausência (e a presença) de humildade do benfeitor com maior frequência, quando comparadas com aqueles de 6 anos. Em síntese, os benfeitores humildes foram considerados mais merecedores 
de retribuição do que os não humildes, principalmente pelos participantes com mais de 9 anos de idade.

\section{O PRESENTE ESTUDO}

Entende-se que a gratidão é uma virtude importante para a educação moral. Ao ser trabalhada em escolas pode aprimorar o convívio entre os indivíduos (LA TAILLE, 2009, 2018, 2019), contrabalançando valores como o individualismo e o hedonismo (FREITAS et al., 2016). Embora Piaget (2014) tenha levantado a hipótese de que a gratidão se desenvolveria desde a infância, apenas recentemente realizaram-se estudos sistemáticos sobre a trajetória do desenvolvimento da gratidão na infância e adolescência (e.g., FREITAS et al., 2016; MERÇON-VARGAS et al., 2016; TUDGE et al., 2015; WANG; WANG; TUDGE, 2015).

Essas pesquisas, realizadas em contextos culturais diferentes, atualizam e ampliam os conhecimentos trazidos pelo pioneiro estudo de Baumgarten-Tramer (1938). Na literatura disponível sobre gratidão não se encontraram, contudo, estudos que tenham investigado quem são, para os jovens, seus benfeitores. Todavia, essa questão é importante, na medida em que diversas pesquisas (BECKER; SMENNER, 1986; MORGAN; GULLIFORD, 2018; SIQUEIRA; FREITAS, 2016) indicam que as características do benfeitor podem influenciar a gratidão.

Realizou-se, então, um estudo com o objetivo de investigar quem são os benfeitores apontados por crianças e adolescentes. Examinaram-se relações entre tipos de benfeitor, idade, tipos de desejo e formas de gratidão. Conforme resultados de estudos (BECKER; SMENNER, 1986; GORDON et al., 2004), a gratidão frequentemente é relacionada a pessoas próximas. Considerando-se esses dados levantou-se a hipótese de que os benfeitores são, em sua maioria, indivíduos que convivem cotidianamente com os jovens.

Outras pesquisas (e.g., MORGAN; GULLIFORD, 2018; VALE; ALENCAR, 2009) indicam que juízos sobre o benfeitor 
se modificam com a idade e que as crianças têm preferência por benfeitores próximos. Assim, hipotetizou-se que menções a pessoas próximas são mais frequentes em crianças (entre 7 e 11 anos) quando comparadas com adolescentes (entre 12 e 14 anos). Este trabalho utilizou o critério etário do Estatuto da Criança e do Adolescente/ECA (BRASIL, 1990) para diferenciar crianças e adolescentes.

Pesquisas sobre gratidão que enfocaram tipos de desejos (FREITAS et al., 2016; MERÇON-VARGAS et al., 2016; TUDGE et al., 2015; WANG; WANG; TUDGE, 2015) não investigaram relações com o benfeitor. Entretanto, alguns autores (CROCKET, 2016; TAQUET et al., 2016) afirmaram que atividades hedonistas, por serem prazerosas e imediatistas, são acompanhadas por pessoas familiares, as quais estimulam ainda mais esse tipo de satisfação. A família e os amigos costumam ser os primeiros lembrados ao se fazer uma festa ou ir ao cinema, por exemplo. Por isso, testou-se a hipótese de que desejos voltados a ganhos imediatos (hedonistas) estão relacionados a benfeitores próximos.

A literatura (e.g., ROSHANDEL; HUDLEY, 2018) também aponta que profissionais, como professores e treinadores, estão em posição para dar suporte aos desejos dos jovens relacionados à carreira e à vida acadêmica. Eles podem contribuir com a conquista de inúmeros desafios de crianças e adolescentes, tais como conseguir uma vaga na universidade ou participar de campeonatos. Assim, estabeleceu-se como hipótese que desejos voltados ao bem-estar próprio, por serem projetados no futuro, estarão associados a benfeitores do mundo profissional.

Diversos autores (e.g., LA TAILLE, 2018, 2019; MENIN, 2019; SAVATER, 1993) sugerem que ações voltadas ao convívio com outras pessoas podem trazer uma vida melhor para os seres humanos. Ao mesmo tempo em que todos podem ser beneficiados a partir de um convívio melhor com outras pessoas, todos também podem contribuir para que isso aconteça. Diante disso, 
testou-se a hipótese de que desejos direcionados ao bem-estar de outros estão relacionados a todos.

Estudos sobre as formas de gratidão (BAUMGARTEN-TRAMER, 1938; FREITAS et al., 2016; MERÇON-VARGAS et al., 2016; TUDGE et al., 2015; WANG; WANG; TUDGE, 2015) não examinaram relações com o benfeitor. Assim, nesta investigação, apesar de não terem sido criadas hipóteses, analisou-se a relação entre gratidão verbal e benfeitores do mundo profissional, da mesma maneira como entre gratidão conectiva e benfeitores próximos.

\section{MÉTODO}

A presente pesquisa é qualitativa, de levantamento e descritiva. A seguir, detalham-se informações sobre os participantes, o instrumento, além dos procedimentos de coleta e análise de dados.

\section{Participantes}

Participaram do presente estudo 283 crianças e adolescentes de 7 a 14 anos $(M=10,86, D P=2,14)$, de ambos os sexos (53,7\% de meninas). Os jovens foram escolhidos por conveniência, em escolas públicas $(71,4 \%)$ e privadas $(28,6 \%)$ de Porto Alegre - RS, selecionadas de forma não aleatória. Oito participantes foram excluídos da amostra inicial de 291 por não estarem de acordo com o critério etário.

\section{Instrumento}

Utilizou-se a versão em português do The Wishes and Gratitude Survey - WAGS (FREITAS; TUDGE; MCCONNELL, não publicado). O instrumento baseou-se no estudo de Baumgarten-Tramer (1938), sendo constituído pelas seguintes perguntas: (a) "O que tu mais queres?" (b) "O que tu farias para a pessoa que te desse o que tu mais queres?" (c) "Quem é esta pessoa?” e (d) "Há mais alguma coisa que tu deverias fazer para a pessoa que te desse o que tu mais queres? Por quê?". 


\section{Procedimentos de coleta e análise de dados}

Após a aprovação do projeto de pesquisa pelo Comitê de Ética em Pesquisa do Instituto de Psicologia da Universidade Federal do Rio Grande do Sul (UFRGS) (protocolo $\mathrm{n}^{\circ}$ 33603514.6.0000.5334), realizou-se contato com a direção das escolas, que assinou um documento autorizando a realização do estudo. Os pais ou responsáveis legais dos participantes assinaram o Termo de Consentimento Livre e Esclarecido. As crianças e os adolescentes assinaram o Termo de Assentimento. Coletaram-se os dados em pequenos grupos compostos pelos jovens interessados em participar da pesquisa, em salas de aula disponibilizadas pelas escolas. O questionário foi respondido por escrito.

As respostas dos participantes sobre tipos de desejo (primeira pergunta da $W A G S$ ), formas de gratidão (segunda pergunta) e tipos de benfeitor (terceira pergunta) foram submetidas à análise de conteúdo (LAVILLE; DIONNE, 1999). Para classificação das duas primeiras questões utilizaram-se categorias de estudos anteriores (BAUMGARTEN-TRAMER, 1938; FREITAS et al., 2016; MERÇON-VARGAS et al., 2016; TUDGE et al., 2015; WANG; WANG; TUDGE, 2015). Para a terceira questão, seguiu-se o modelo misto (LAVILLE; DIONNE, 1999): partiu-se de codificação proposta previamente e, durante o processo de classificação, quando necessário, modificaram-se ou criaram-se categorias.

Os tipos de desejo foram classificados como: hedonistas, relativos ao bem-estar próprio e relacionados ao bem-estar de outros. O índice de concordância (Kappa) variou entre 0,87 e 0,94 . As formas de gratidão foram: verbal, concreta e conectiva. O Kappa variou de 0,79 a 0,94. As respostas sobre os tipos de benfeitor foram codificadas em sete categorias: próximo, profissional, imaterial, eu, ninguém, todos e não sei.

Os benfeitores próximos referem-se a familiares - tanto da família nuclear quanto da estendida - e amigos (por exemplo, "A minha mãe"; "João, meu amigo"). Os "profissionais" incluem pessoas distantes, as quais fazem parte do mundo do trabalho, 
tais como professores, treinadores e outros trabalhadores ("A professora de Ciências"; “Talvez um empresário de negócios”). Os "imateriais" remetem a seres ideativos ou do plano espiritual, incluindo entidades religiosas e personagens fantasiosos ("Deus"; "Uma fada dos desejos").

$\mathrm{Na}$ categoria "eu", os participantes indicaram que eles mesmos seriam os benfeitores ("Não tem pessoa, só eu posso"; "Esta pessoa sou eu”). A classificação "ninguém” engloba respostas de que não havia pessoa alguma que pudesse proporcionar a benesse ("Ninguém"). A divisão "todos" indica que o benfeitor seria todo mundo ou qualquer pessoa ("Todos poderiam ajudar, não há pessoa específica"; "Qualquer uma pessoa"). A classe "não sei" remete a respostas daqueles que não sabiam quem poderia dar o benefício ("Não sei, não posso prever o futuro"; “Eu ainda não sei”). As respostas que não puderam ser classificadas em nenhuma das sete categorias foram codificadas como "outros" ("Agatha"; "Um travesseiro"). O Kappa variou de 0,83 a 1 .

Realizaram-se análises descritivas, com os tipos de benfeitor e testes qui-quadrado, com as seguintes duplas de variáveis dicotômicas: benfeitores próximos e grupos etários (entre 7 e 11 anos e entre 12 e 14); desejos voltados a ganhos imediatos e benfeitores próximos; desejos focados no bem-estar próprio e benfeitores do mundo profissional; desejos direcionados ao bem-estar de outros e todas as pessoas; gratidão verbal e benfeitores do mundo profissional; e gratidão conectiva e benfeitores próximos.

\section{RESULTADOS}

No total, categorizaram-se 300 respostas referentes aos tipos de benfeitor. O número de respostas foi maior que o de participantes, porque alguns mencionaram mais de um tipo. $\mathrm{O}$ Quadro 1 mostra os tipos de benfeitor e suas frequências. 


\section{Quadro 1 - Frequências dos tipos de benfeitor por grupo etário}

\begin{tabular}{|c|c|c|c|c|c|c|c|c|c|}
\hline \multirow{2}{*}{$\begin{array}{c}\text { Ida- } \\
\text { de }\end{array}$} & \multicolumn{7}{|c|}{ Tipos de benfeitor } & \multirow{2}{*}{$\begin{array}{c}\text { To- } \\
\text { tal }\end{array}$} \\
\cline { 2 - 10 } & $\begin{array}{c}\text { Pró- } \\
\text { ximo }\end{array}$ & $\begin{array}{c}\text { Profis- } \\
\text { sional }\end{array}$ & $\begin{array}{c}\text { Ima- } \\
\text { terial }\end{array}$ & Eu & $\begin{array}{c}\text { Nin- } \\
\text { guém }\end{array}$ & $\begin{array}{c}\text { To- } \\
\text { dos }\end{array}$ & $\begin{array}{c}\text { Não } \\
\text { sei }\end{array}$ & $\begin{array}{c}\text { Ou- } \\
\text { tros }\end{array}$ & \\
\hline $\mathbf{7 - 1 1}$ & 115 & 11 & 7 & 5 & 1 & 5 & 12 & 8 & 164 \\
\hline $\begin{array}{c}12- \\
14\end{array}$ & 79 & 10 & 4 & 8 & 1 & 6 & 16 & 12 & 136 \\
\hline $\begin{array}{c}\text { To- } \\
\text { tal }\end{array}$ & 194 & 21 & 11 & 13 & 2 & 11 & 28 & 20 & 300 \\
\hline
\end{tabular}

Fonte: Dados de pesquisa dos próprios autores.

A hipótese de que os benfeitores seriam, em sua maioria, pessoas que convivem com os jovens recebeu suporte empírico. Além disso, conforme previsto, a menção a pessoas próximas foi mais frequente em crianças do que em adolescentes. Houve associação significativa entre benfeitores próximos e os grupos etários, $\chi^{2}(1)=5,88$, $(p<0,05)$. As crianças tiveram 1,9 vezes mais chances de mencionar um benfeitor próximo que os adolescentes.

Todas as três hipóteses que tratavam da relação entre benefício e benfeitor receberam suporte empírico. Benesses voltadas a ganhos imediatos e benfeitores próximos associaram-se significativamente, $\chi^{2}(1)=10,50,(p<0,05)$. Os jovens que mencionaram desejos hedonistas tiveram 2,3 vezes mais chances de remeter a benfeitores próximos. Benefícios voltados ao bem-estar próprio e benfeitores do mundo profissional relacionaram-se significativamente, $\chi^{2}(1)=7,17,(p<0,05)$.

Indivíduos que se referiram a benefícios para o bem-estar próprio tiveram 4,8 vezes mais chances de citar benfeitores do mundo profissional. Benefícios direcionados ao bem-estar de outros se associaram significativamente a todas as pessoas, $\chi^{2}(1)$ $=34,23,(\mathrm{p}<0,05)$. Os participantes que mencionaram benesses 
para o bem-estar de outros tiveram 31,5 vezes mais chances de se remeter a todo mundo.

Não houve associações estatisticamente significativas entre gratidão verbal e benfeitores do mundo profissional, $\chi^{2}(1)=$ 1,15, ( $\mathrm{p}>0,05)$, nem entre gratidão conectiva e benfeitores próximos, $\chi^{2}(1)=0,67,(p>0,05)$.

\section{DISCUSSÃO}

Uma educação moral que incentive o desenvolvimento de virtudes torna possível um convívio mais genuíno entre os indivíduos (LA TAILLE, 2018, 2019). A gratidão tem a possibilidade de contrabalançar valores que não raras vezes trazem prejuízos à vida dos jovens, tais como o individualismo e o hedonismo, e dar ênfase ao convívio com outros seres humanos (FREITAS et al., 2016). Conhecer quem as crianças e os adolescentes indicam como seus benfeitores é um passo importante para se compreender a gratidão como um todo.

Neste estudo a maior parte dos jovens, de todas as idades, mencionou benfeitores próximos. Esses dados complementam os resultados da pesquisa de Becker e Smenner (1986), na qual as crianças tenderam a não serem gratas a benfeitores desconhecidos, e a de Gordon et al. (2004), em que os jovens demonstraram preferência por pessoas próximas em relações de gratidão.

A escolha de pessoas próximas como principais benfeitores pode refletir uma esperança em meio aos valores superficiais da sociedade atual. Relacionamentos com pessoas próximas costumam ser os mais íntimos, duradouros e profundos que se tem durante a vida. Os jovens desta pesquisa parecem preferir estabelecer relações firmes com a família e amigos a nutrir relacionamentos frágeis e efêmeros, os quais, segundo La Taille (2019), são típicos da contemporaneidade.

No entanto, a preferência por indivíduos familiares parece diminuir com o passar dos anos. As crianças mencionaram benfeitores próximos com maior frequência que os adolescentes. 
Isso pode ter ocorrido, por um lado, porque, conforme Piaget (1994, 2014), crianças com até 12 anos ainda são muito motivadas pela afeição por seus pais e outras pessoas próximas. Apenas na adolescência o indivíduo amplia consideravelmente seu ciclo social e passa a ter relações com pessoas com as quais tem pouca ou nenhuma proximidade. Por outro lado, devido à ampliação do ciclo social, o adolescente pode ser influenciado por colegas e normas sociais, passando a valorizar mais a quantidade dos relacionamentos que sua qualidade. As redes sociais - muito populares entre os adolescentes - parece ser exemplo dessa superficialidade. Nelas, é comum que os usuários adicionem um grande número de pessoas ao seu círculo de amizades, mesmo sem terem um contato mais profundo com boa parte delas.

Paradoxalmente, os jovens que mencionaram benfeitores próximos tenderam a se referir a desejos hedonistas. Conforme La Taille (2009), o hedonismo é característico da sociedade atual, indicando ausência de projeção no futuro. Tratam-se de atividades que permitem as pessoas se sentirem bem, terem algum tipo de prazer momentâneo.

Mesmo que pareça contraditório, as pessoas consideradas mais adequadas para desfrutar de situações imediatistas são indivíduos próximos, como amigos e parentes (CROCKET, 2016; TAQUET et al., 2016). Todavia, embora seja coerente considerar que pessoas familiares são boas companhias para desfrutar de atividades hedonistas, elas não servem apenas para isso. Afinal, é com pessoas familiares que os indivíduos, muitas vezes, realizam as ações significativas de suas vidas.

A possibilidade de adiar o prazer e fazer planos futuros é uma maneira de não se submeter ao hedonismo (LA TAILLE, 2009). Nesta pesquisa os jovens que mencionaram desejos projetados no futuro, mas voltados ao bem-estar próprio, tiveram a tendência de se referir a benfeitores profissionais. Para se atingirem metas pessoais (por exemplo, ter um bom emprego, 
ser alguém na vida), é importante contar com a ajuda de pessoas capacitadas, tais como professores, treinadores ou empresários.

Alguns profissionais, especialmente os professores, estão em posição de dar suporte aos sonhos e desejos dos jovens, podendo auxiliá-los a alcançar metas importantes para o futuro (ROSHANDEL; HUDLEY, 2018). Esses trabalhadores têm a possibilidade, inclusive, de ajudar diretamente na aquisição de atributos necessários ao desenvolvimento profissional de crianças e adolescentes. Por exemplo, se um indivíduo deseja tornar-se um jogador de futebol, seu treinador pode auxiliá-lo a desenvolver certas habilidades. Além disso, pode dar-lhe a oportunidade de jogar uma partida importante e ser visto por técnicos de times famosos.

Desejos voltados ao bem-estar de outros, além de contrabalançarem o hedonismo, por serem projetados no tempo, propiciam melhor convivência com outras pessoas, visto que visam beneficiá-las. Neste estudo, os jovens que mencionaram esse tipo de desejo tenderam a afirmar que todos são responsáveis por realizá-lo. Tal resultado foi particularmente interessante devido ao seu tamanho de efeito: indivíduos que se remeteram a benefícios para o bem-estar de outros tiveram 31,2 vezes mais chances de se referir a todo mundo. Isso pode representar uma esperança em meio ao imediatismo e individualismo da contemporaneidade. Afinal, os jovens já admitem a importância de que todos se esforcem para auxiliar outras pessoas.

O cuidado com o outro é visto, não como uma responsabilidade individual, mas como obrigação de toda a sociedade. Além disso, com a noção de que cabe a todos beneficiar outras pessoas, os jovens sugeriram que os indivíduos precisam ter atitudes virtuosas. As virtudes, principalmente aquelas voltadas ao cuidado com o outro, foram vistas como função do ser humano.

Atitudes relacionadas à generosidade, gratidão e compaixão prevaleceram no lugar do individualismo e do egoísmo. Esse resultado é importante, visto que as virtudes possibilitam um 
melhor convívio social (MENIN, 2019; LA TAILLE, 2018). Um mundo virtuoso é um lugar onde não há encurtamento da vida coletiva, mas sim multiplicação de relacionamentos profundos e genuínos. A depender dos jovens, as pessoas ajudariam mais os outros, estabeleceriam um melhor convívio e teriam uma "vida boa humana" (SAVATER, 1993, p. 74).

Não foram encontradas relações entre gratidão verbal e benfeitores profissionais. Uma possibilidade é que o "dizer obrigado”, apesar de servir para manter a boa convivência entre pessoas pouco conhecidas (LA TAILLE, 2001), também pode ser expressão verbal de um agradecimento genuíno, sendo acompanhada inclusive de tipos de gratidão mais refinados. Assim, não seria devida a apenas alguns profissionais, mas a qualquer pessoa digna de agradecimento. Não houve associação entre gratidão conectiva e benfeitores próximos. Uma explicação possível para esse resultado é que, a partir do momento em que o indivíduo adquire a habilidade de se colocar no lugar do outro, ele pode fazê-lo em relação a qualquer pessoa (PIAGET, 2014) e não apenas daquelas com quem tem maior proximidade.

\section{CONSIDERAÇÕES FINAIS}

O presente estudo investigou quem são os benfeitores apontados por crianças e adolescentes de 7 a 14 anos, assim como relações desses benfeitores com a idade, os tipos de desejo e de gratidão desses jovens. Os resultados desta pesquisa, juntamente com outros sobre benfeitor (e.g., MORGAN; GUILLIFORD, 2018; SIQUEIRA; FREITAS, 2016) e beneficiário (e.g., BAUMGARTEN-TRAMER, 1938; FREITAS et al., 2016; MERÇON-VARGAS et al., 2016; TUDGE et al., 2015), contribuem para um melhor entendimento da gratidão.

Entende-se que essa é uma virtude importante para a educação moral. Em primeiro lugar, porque tratar de temas morais nas escolas, conforme orienta os PCN (BRASIL, 1998), estimula o desenvolvimento dos alunos (PIAGET, 1998) e permite um 
convívio mais genuíno entre os indivíduos (LA TAILLE, 2001, 2018). Em segundo, porque, no caso específico da gratidão, torna-se possível contrabalançar valores, tais como o individualismo e o hedonismo (FREITAS et al., 2016), os quais são frequentes na sociedade contemporânea (MENIN, 2019; LA TAILLE, 2019).

Quando os jovens têm uma convivência de qualidade com outras pessoas, eles têm a possibilidade de viver melhor e encontrar sentido em suas vidas (SAVATER, 1993). Os resultados deste estudo auxiliam a identificar aspectos admiráveis nas crianças e adolescentes, criando a possibilidade de entendê-los e estimulá-los. Por exemplo, a maior parte das crianças e adolescentes escolheu, como seus benfeitores, pessoas próximas, ou seja, aquelas com as quais normalmente se tem relacionamentos profundos e duráveis.

Além disso, alguns jovens indicaram que é papel de todos realizar benefícios voltados ao bem-estar de outros. Desse modo, vislumbra-se a relevância de se fomentar relações mais profundas e o cuidado com os outros, pois assim possibilita-se combater a efemeridade dos relacionamentos e o hedonismo da sociedade.

Uma limitação do estudo foi não ter encontrado relações entre tipos de benfeitor e formas de gratidão. É necessário realizar outras pesquisas para verificar se, de fato, não há associação entre essas variáveis ou se o método utilizado não foi eficaz para evidenciá-la. Sugere-se, ainda, investigar a relação entre benfeitor e tipos de desejo em adultos. Assim, seria possível examinar se a ideia de que todos são responsáveis por realizar benefícios para outras pessoas também está presente nessa fase da vida.

\section{REFERÊNCIAS}

ARAGÃO et al. Contos de fadas e a formação de valores morais: projeção do bem e do mal na literatura infantil. Cadernos de Educação - Reflexões e debates, São Paulo, v. 17, n. 35, p. 121-146, 2018. 
BAUMGARTEN-TRAMER, F. "Gratefulness" in children and young people. Journal of Genetic Psychology, [S.1.], v. 53, p. 53-66, 1938.

BECKER, J. A.; SMENNER, P. C. The spontaneous use of thank you by preschoolers as a function of sex, socioeconomic status, and listener status. Language in Society, [S.1.], v. 15, p. 537-546, 1986.

BRASIL. Base Nacional Comum Curricular. Educação é a base. Brasília, DF: MEC, 2018. Disponível em: http://basenacionalcomum.mec.gov.br/ images/BNCC_EI_EF_110518_versaofinal_site.pdf. Acesso em: 4 jun. 2019.

Lei no 8.069, de 13 de julho de 1990. Dispõe sobre o Estatuto da Criança e do Adolescente e dá outras providências. Brasília, DF: Presidência da República, 1990. Disponível em: http://www.planalto.gov.br/ccivil_03/ leis/18069.htm. Acesso em: 1 jun. 2019.

Parâmetros Curriculares Nacionais: Terceiro e quarto ciclos do Ensino Fundamental. Brasília, DF: Secretaria de Educação Fundamental, 1998. Disponível em: http://portal.mec.gov.br/seb/arquivos/pdf/introducao.pdf e http://portal.mec.gov.br/seb/arquivos/pdf/ttransversais.pdf. Acesso em: 4 jun. 2019.

Resolução $\mathrm{n}^{\circ}$ 2, de $\mathbf{1}^{\circ}$ de julho de 2015. Define as Diretrizes Curriculares Nacionais para a formação inicial em nível superior (cursos de licenciatura, cursos de formação pedagógica para graduados e cursos de segunda licenciatura) e para a formação continuada. Brasília, DF: MEC, 2015. Disponível em: http://portal.mec.gov.br/docman/agosto-2017-pdf/70431res-cne-cp-002-03072015-pdf/file. Acesso em: 2 jun. 2019.

COUTO, L. L.; ALENCAR, H. M. Concepção de justiça e injustiça de docentes do ensino fundamental. Psicologia em Pesquisa, Juiz de Fora, v. 11, n. 1, p. 34-43, 2017.

CROCKET, H. An ethic of indulgence? Alcohol, Ultimate Frisbee and calculated hedonism. International Review for the Sociology of Sport, [S.1.], v. 51, n. 5, p. 617-631, 2016.

DELLAZZANA-ZANON, L. L. et al. Pesquisas em desenvolvimento moral: contribuições da psicologia brasileira. Psico, Porto Alegre, v. 44, n. 3, p. 342-351, 2013.

FREITAS, L. B. L. et al. A compreensão da gratidão e teoria da mente em crianças de 5 anos. Psicologia: Reflexão e Crítica, Porto Alegre, v. 25, n. 2, p. 330-338, 2011.

et al. Relações entre desenvolvimento da gratidão e tipos de valores em jovens. Psico-USF, Itatiba, v. 21, n. 1, p. 13-24, 2016. 
; TUDGE, J.; MCCONNELL, T. The wishes and gratitude survey.

Não publicado.

GALIAN, C. Os PCN e a elaboração de propostas curriculares no Brasil. Cadernos de Pesquisa, São Paulo, v. 44, n. 153, p. 648-669, 2014.

GORDON, A. et al. What are children thankful for? An archival analysis of gratitude before and after the attacks of September 11. Journal of Applied Developmental Psychology, [S.1.], v. 25, n. 5, p. 541-553, 2004.

LA TAILLE, Y. Desenvolvimento moral: a polidez segundo as crianças. Cadernos de Pesquisa, São Paulo, n. 114, p. 89-119, 2001.

Formação ética: do tédio ao respeito de si. Porto Alegre: Artmed, 2009.

Moral e contemporaneidade. Schème, Marília, v. 11, n. especial, p. 6-24, 2019.

Toward a psychological study of the virtues. In: TUDGE, J. R. H.; FREITAS, L. B. L. (Org.). Developing gratitude in children and adolescents. Cambridge: Cambridge University Press, 2018. cap. 2, p. 25-41.

LAVILLE, C.; DIONNE, J. A construção do saber: manual de metodologia da pesquisa em Ciências Humanas. Porto Alegre: Artes Médicas, 1999.

MCCONNELL, T. Gratitude, rights and moral standouts. Ethical Theory and Moral Practice, [S.1.], v. 20, n. 2, p. 279-293, 2017.

MENDONÇA, S. E. et al. The development of gratitude in seven societies: Cross-cultral highlights. Cross-Cultural Research, [S.l.], v. 58, n. 1, p. 135 $150,2018$.

MENIN, S. Adesão a valores sociomorais na contemporaneidade: um estudo com escolares e Ensino Fundamental e Médio. Schème, Marília, v. 11, n. especial, p. 86-122, 2019.

MERÇON-VARGAS, E. et al. Wishes and gratitude of students from private and public schools. Psico-USF, Itatiba, v. 21, n. 3, p. 651-662, 2016.

MORGAN, B.; GUILLIFORD, L. Assessing influences on gratitude experience. In: TUDGE, J. R. H.; FREITAS, L. B. L. (Org.). Developing gratitude in children and adolescents. Cambridge: Cambridge University Press, 2018. cap. 4 , p. 65-88.

PALHARES, F. et al. The development of gratitude in Brazilian children and adolescents. Cross-Cultural Research, [S.1.], v. 52, n. 1, p. 31-43, 2018.

PIAGET, J. O juízo moral na criança. São Paulo: Grupo Editorial Summus, 1994. 
Os procedimentos da educação moral. In: PARRAT-DAYAN, S.; TRYPHON, A. Sobre a pedagogia: Textos inéditos. São Paulo: Casa do Psicólogo, 1998. cap. 1, p. 25-58.

Relações entre a afetividade e a inteligência no desenvolvimento mental da criança. Rio de Janeiro: WAK, 2014.

RAVA, P.; FREITAS, L. B. L. Gratidão e sentimento de obrigatoriedade na infância. Psico-USF, Itatiba, v. 18, n. 3, p. 383-394, 2013.

ROSHANDEL, S.; HUDLEY, C. Role of teachers in influencing the development of adolescents' possible selves. Learning Environments Research, [S.1.], v. 21, n. 2, p. 211-228, 2018.

SAVATER, F. Ética para meu filho. São Paulo: Martins Fontes, 1993.

SIQUEIRA, F. Q.; FREITAS, L. B. Desenvolvimento das relações entre humildade e gratidão na infância. Estudos e Pesquisas em Psicologia, Rio de Janeiro, v. 16, n. 3, p. 854-872, 2016.

TAQUET, M. et al. Hedonism and the choice of everyday activities. Proceedings of the National Academy of Sciences, [S.1.], v. 113, n. 35, p. 9769-9773, 2016.

TUDGE et al. Methods for studying the virtue of gratitude cross-culturally. Cross-Cultural Research, [S.1.], v. 58, n. 1, p. 19-30, 2018.

et al. The wishes and expression of gratitude of youth. Ribeirão Preto: Paidéia, v. 25, n. 62, p. 281-288, 2015.

VALE, L.; ALENCAR, H. Generosidade para com amigo, desconhecido e inimigo: juízos morais de crianças e adolescentes. Interação em Psicologia, Curitiba, v. 13, n. 2, p. 299-310, 2009.

WANG, D; WANG, Y. C.; TUDGE, J. R. H. Expressions of gratitude in children and adolescents: Insights from China and the United States. Journal of Cross-Cultural Psychology, [S.1.], v. 46, n. 8, p. 1039-1058, 2015.

NOTA DE AGRADECIMENTO

Os autores agradecem a John Templeton Foundation (Research Award \# 43150), a CAPES e ao CNPq (Processo n³02688/2015-3) pelo apoio financeiro recebido.

\section{SOBRE OS AUTORES}

Felipe Queiroz Siqueira é Mestre em Psicologia pela Universidade Federal do Rio Grande do Sul (UFRGS), Doutorando do Programa de Pós-graduação em Psicologia da UFRGS e membro do Laboratório de Psicologia e Epistemologia 
Genética (LAPEGE). Recebe financiamento de pesquisa da CAPES. E-mail: felipeqsiqueira@gmail.com

Lia Beatriz de Lucca Freitas é Doutora em Psicologia pela Universidade de São Paulo (USP), Professora Titular da Universidade Federal do Rio Grande do Sul (UFRGS), onde coordena o LAPEGE, e recebe Bolsa de Produtividade em Pesquisa do CNPq. E-mail: lblf@ufrgs.br 